\title{
Computer Vision Coaching Microsurgical Laboratory Training: Prime (Proficiency Index in Microsurgical Education) Proof of Concept
}

\author{
Marcelo Magaldi Oliveira ( $\sim$ mmagaldi@hotmail.com ) \\ Lucas Quittes \\ UFMG: Universidade Federal de Minas Gerais \\ POLLYANA HELENA VIEIRA COSTA \\ UFMG: Universidade Federal de Minas Gerais \\ Taise Mosso Ramos \\ UFMG: Universidade Federal de Minas Gerais \\ Ana Clara Fidelis Rodrigues \\ UFMG: Universidade Federal de Minas Gerais

\section{Arthur Nicolato} \\ UFMG: Universidade Federal de Minas Gerais \\ Jose Augusto Malheiros \\ UFMG: Universidade Federal de Minas Gerais
}

UFMG: Universidade Federal de Minas Gerais https://orcid.org/0000-0002-5932-200X

\section{Research Article}

Keywords: microsurgery, cerebrovascular surgery, computer vision, surgical training, neurosurgical training, neurosurgical education, neurosurgical simulation

Posted Date: May 10th, 2021

DOl: https://doi.org/10.21203/rs.3.rs-495309/v1

License: @ (i) This work is licensed under a Creative Commons Attribution 4.0 International License. Read Full License

Version of Record: A version of this preprint was published at Neurosurgical Review on October 31st, 2021. See the published version at https://doi.org/10.1007/s10143-021-01663-6. 


\section{Abstract}

Objective: Computer vision (CV) feedback could be aimed as a constant tutor to guide ones proficiency during microsurgical practice in controlled environments.

Methods: Five neurosurgeons with different levels of microsurgical expertise performed simulated vessel dissection and micro-suture in an ex-vivo model for posterior computer analysis of recorded videos. Computer program called PRIME (PRoficiency Index of Microsurgical Education) used in this research recognized color labeled surgical instruments, from downloading videos into a platform, with a range of motion greater than $3 \mathrm{~mm}$, for objective evaluation of number of right and left hand movements. A proficiency index of 0 to 1 was pre established in order to evaluate continuous training improvement.

Results: PRIME computer program captured all hand movements executed by participants, except for small tremors or inconsistencies that have a range of motion inferior to $3 \mathrm{~mm}$. Number of left and right hand movements were graphically expressed in order to guide more objective and efficacious training for each trainee, without requiring body sensors and cameras around the operating table. Participants with previous microsurgical experience showed improvement from 0.2 to 0.6 ( $p<0.05)$, while novices had no improvement. Proficiency index set by $\mathrm{CV}$ was suggested, in a self-challenge and self-coaching manner.

Conclusions: PRIME would offer the capability of constant laboratory microsurgical practice feedback under CV guidance, opening a new window for oriented training without a tutor or specific apparatus regarding all levels of microsurgical proficiency. Prospective, large data study is needed to confirm this hypothesis.

\section{Introduction}

Computer vision (CV) can be defined as how computers can gain high-level of understanding from digital images or videos. When added to machine learning $(\mathrm{ML})$ they can be pathways to reach artificial intelligence (Al) by data recognition, interpretation and analysis resulting in information feedback to define a process. Al is defined as the study of any non-biological device that perceives its environment and takes actions that maximize its chance of successfully achieving its goals [1-6]. Cerebrovascular microsurgical technique guidance from CV, ML or Al has not been reported to our knowledge.

Among neurosurgeons, the ones working with brain vessel microsurgery are considered skilled ones, what is generally acquired after exhaustive laboratory training $[7,8]$. Nevertheless, surgical fine hand movements have been objectively evaluated by body sensors and cameras, requiring specific apparatus placed into the operating room, in order to provide computerized feedback analysis of performance. Despite of being innovative this technology is not cheap neither practical, especially to be used in any microsurgical laboratory to guide performance. Acquiring data from surgical instruments movements by pre-determined color markers differentiated from surgical field structures is an original idea explored by our group under CV methodology.

Controlled environment training, as a microsurgical laboratory, should be mandatory to learn and practice specific surgical techniques with rigor, in order to increase patient safety through quality assurance $[9,10]$. Indeed, microsurgical competence is not just acquired but, in a strict sense, it needs to be maintained [11]. A parallel can be traced between micro-surgeons and Olympic athletes, as excellent achievements today do not mean good accomplishment tomorrow [11-13]. Constant analysis and training is mandatory, but finding a mentor to be always present is utopic. 
Our aim is to report the proof of concept of CV coaching microsurgical laboratory training on a placenta high fidelity simulator focusing in number of surgical maneuvers, without tutor and sensors, in order to reach proficiency.

\section{Material And Methods}

This study consisted in microsurgical movements captured by CV through simulation videos downloaded to a platform after dissecting and suturing vessels in a safe environment, as a microsurgical laboratory, using a high fidelity placenta model.

Microsurgical training using human placenta has advantages and characteristics published by the main author, regarding model preparation, anatomical description, validation and quality assurance capacity justifying its usage in this study [7-9]. Research conduction ranged from January 2019 to January 2021, being previously approved by the ethical committee.

Two freshmen, 2 senior neurosurgical residents and 1 cerebrovascular neurosurgeon voluntarily joined this study, consenting data release for publication. Each participant repeated 3 simulation sessions, with 1 week apart, comprising $1.3 \mathrm{~mm}$ diameter human placenta vessel dissection, $1 \mathrm{~cm}$ longitudinal arteriotomy and subsequent micro-suture with 9-0 Nylon (Video 1). A sailing bag with colored die (Red Gouache $1 \mathrm{gram}: 200 \mathrm{ml}$ of sailing) connected to an infusion line placed one meter above simulator perfused placenta vessels. Temporary aneurysm clips applied proximally and distally (reference was the sailing bag) interrupted the simulated flow, so once released leakage could be promptly detected. A computer program developed by the authors' called PRIME (PRoficiency Index in Microsurgical Education) counted surgical maneuvers done with the right and left hand by recognizing color labeled surgical instruments moving more than $3 \mathrm{~mm}$ over the operating field. Simulation videos were downloaded on PRIME platform in order to provide surgeons the feedback in a numerical graphic pattern. No body sensors or special video cameras, other than microscope regular recording, was used in this study.

PRIME recognition of motion used microsurgical instruments tagged with a $15 \mathrm{~mm}$ tape with fluorescent colors, placed on each instrument arm about $4 \mathrm{~cm}$ from the tip. Complete differentiation from biological tissue during operative motion was obtained with yellow tags on left instruments and green tags on right ones, allowing complete color differentiation from biological tissues. Instruments moving less than $3 \mathrm{~mm}$ received no punctuation because pre simulation consensus between authors and trainees agreed that they were unintentional motions.

Endpoints for feedback regarding microsurgical performance analysis consisted of total time to execute proposed tasks and number of right and left hand movements (Table 1) (Figure 1).

PRIME final score ranged from 0 to 1, meaning $0 \%$ to $100 \%$ of performance improvement from each subsequent recorded video download at the platform. Reduced time of whole procedure 0.01 to 6 minutes faster than from previous simulation scored 0.1 to 0.3 , so each 2 minutes of reduced time counted 0.1 points. Range of instruments motion scored from 0.4 to 0.7 points, with each $10 \%$ of movement reduction from previous essay scoring 0.1 , up to a maximum of $70 \%$ less movements (0.7). In order to ameliorate $100 \%$ one needed to reduce 6 minutes and $70 \%$ of movements from previous session (Table 1). PRIME offers the capacity of self-evaluation by intra-rater analysis, and cannot be used to compare performances of different persons, as used in inter-rater analysis. We stratified individuals in three groups: junior residents; senior residents; and cerebrovascular micro-surgeon. Paired t- test was used to evaluated whether there were differences between sessions 1 and 2; sessions 1 and 3 . The significance 
level adopted was $5 \%(p<0.05)$. As study sample is small, aiming a proof of concept publication, s simple comparison of reduced movement percentage between easy 1 and 3 was also noted.

\section{Results}

All participants finished all tasks resulting in 15 different data obtained from 5 participants, with 3 different scores for each one (Table 1). Improvements occurred in time and number of movements by senior residents and cerebrovascular neurosurgeon, but without statistical significance.

Placenta microsurgical videos could be promptly imputed into the computer platform, so PRIME graphic results were rapidly available. Table 1 summarizes PRIME data to target a proficiency index that can vary from 0 to 1 , meaning that 1 is $100 \%$ proficiency. In order to validate this hypothesis, a large data acquisition would be needed, but our scope was just a proof of concept.

PRIME recognized yellow and green colors labeled on microsurgical instruments apart from the simulation field in all 15 simulations (Video 1). Other tried colors had no consistency in computer recognition of independent movements from biological tissues, as labeled colors were mixed with biological tissues appearance.

Chronometer displayed time in standard fashion that was shown in the same screen as hand movements/instruments counting, making it easy to analyze at the end of procedure.

Comparing performance within 3 sessions, junior residents did not improve any parameter based on pre determined scores, probably needing more training to achieve significant proficiency index $(p>0.05)$. Senior residents improved time and number of movements in about $20 \%$, but with no statistical significance $(p>0.05)$, probably due to small sample. Cerebrovascular micro-surgeon had improvements on time and number of hand movements between $20 \%$ and $40 \%$, however with no assessment of statistical significance (1 surgeon only). This highlights the challenging defies of placenta micro-suture simulation and PRIME usefulness in all levels of expertise.

Proficiency index theoretically varied from 0.2 to 0.7 by participant expertise level, just to give examples of how it can be constructed in the future. PRIME final score displayed in Table 1 was just preliminary results, as larger data is necessary for technical validation.

\section{Discussion}

CV, ML and Al are virtual terminologies currently applied to different situations in science and social life. They can be interpreted as a continuum or an isolated technical program in computer engineering. Computer vision would be expressed as a system able to capture information similar to human senses. Machine learning refers to data input as an informative program, analogous to mankind knowledge acquisition. Artificial intelligence can do both of previous described features but provides feedback, so all information are processed and returned to supplier with suggestive directions to be followed, what results in machine influencing human behavior [1-6].

Nowadays, time arrow seems to run faster diminishing the opportunity to dedicate to laboratory training [3]. People frequently have trouble finding time to travel or spent days training microsurgical techniques, so having a machine tutor that can guide technical proficiency parameters as a take home course could be seductive. One can practice microsurgery in his own microscope, instruments and model with PRIME platform feedback. 
This study claims the use of CV terminology, as the methodology comprises of recognizing visual stimulus, transforming that into numbers that guide ones practice. Our data is very small, so we support the research as a proof of concept, as this could be a path for future research including $\mathrm{ML}$ and $\mathrm{Al}$ as being the surgical mentor, either in the laboratory or in real scenario. If the same platform could be used in both practices, laboratory predictive validity would define surgical competency even before it is performed in patients.

The computer algorithm needs consistent color difference in order to obtain CV inputs. The labeled surgical instruments must show this pattern in all surgical fields, so standard tonalities would be used in all interventions making PRIME a universal platform and not only for microsurgery.

An index of microsurgical proficiency could be the target of an apprentice or the continuous goal of an experienced surgeon. As used by many medical specialties boards, knowledge needs firstly to be acquired and proved for posterior systematical maintenance [11-13]. Despite of that, theoretical expertise does not reflect practical one, especially in a highly demanded skill labor as microsurgery [14]. To our knowledge, there is no neurosurgical society that evaluates constantly the level of microsurgical proficiency. Proficiency index would be the summation of all parameters referring to a level of practical expertise in microsurgery. Establishing such a value will depend on statistical analysis of each component referred to final task execution. As described in this study, the 2 evaluated parameters might have different degrees of importance, so finding how much a parameter weights in values would be a future goal.

PRIME long term objective is to determine per operatively or immediate after a microsurgical intervention the level of proficiency reached by a surgeon. As stated before, this report is only a proof of concept, so to delivery such determination, it must be validated with a very large data and statistical analyzes. Its main advantage is the reproducibility and pragmatic usage, as it can be reproduced in any situation where surgical instruments movements are recognized independently using color markers.

Coaching is a traditional concept applied to many physical activities, like sports, but in surgery the Halsted principles of learning by observing a mentorship has resided for decades $[3,7,8]$. Although mentors are considered very experienced professionals, with higher knowledge, they are not capable of observing details that machine could. Regarding this project, time to complete tasks is easily evaluated by tutors, but this metric alone does not mean anything regarding technical proficiency. Counting number of right and left hand movements while holding surgical instruments is an impossible human task. The idea of being coached by a machine is used in some areas, but in microsurgery it might be considered unreliable by some professionals. If proved, it can offer an important educational contribution as having a neurosurgeon being always coached, with potential resident education benefits as all operative actions being objectively monitored.

As placenta cerebrovascular microsurgical simulator has been predictive validated, it gives opportunity to PRIME platform to predict proficiency performance in the laboratory in advance to real surgery, what could potentially increase quality assurance and patient safety. Due to its practicability, the future goal is to use PRIME during real surgery, so real time feedback could be displayed during surgery guiding a specific operation by informing if the surgeon performance is ahead or behind a pre established proficiency level. If PRIME index could not be reached during the procedure, the surgeon might increase concentration or stop the operation due to patient safety reasons.

As this is a proof of concept research, several limitations can be elicited as small number of participants, lack of intra rater statistical consistency and proficiency index suggested by authors without validation. Due to study 
originality, practicability and PRIME preliminary results, authors agreed that pilot results are important to be published at this time to justify a multi-centric, prospective data collection.

PRIME would offer the capability of constant laboratory microsurgical practice feedback under CV guidance, opening a new window for oriented training without a tutor or specific apparatus, regarding all levels of microsurgical proficiency. Prospective, large data study is needed to confirm this hypothesis.

\section{Declarations}

Funding (information that explains whether and by whom the research was supported)

No funding was received for this work.

Conflicts of interest/Competing interests (include appropriate disclosures)

The authors have no personal, financial, or institutional interest in any materials, or devices described in this article.

Availability of data and material (data transparency)

Not applicable.

Code availability (software application or custom code)

Not applicable.

Ethics approval (include appropriate approvals or waivers)

Ethics approval COEP UFMG 0364.0.203.000-11

Consent to participate (include appropriate statements)

All participants consent to participate.

Consent for publication (include appropriate statements)

All participants gave the consent to the publication.

Authors' contributions (All authors must be mentioned)

Marcelo Magaldi Oliveira - conception or design of the work; acquisition, analysis, or interpretation of data for the work; drafting the work or revising; final approval.

Lucas Quittes: acquisition, analysis, or interpretation of data for the work.

Pollyana Helena Vieira Costa: conception or design of the work; acquisition, analysis, or interpretation of data for the work; drafting the work or revising; final approval.

Taise Mosso Ramos: acquisition, analysis, or interpretation of data for the work.

Ana Clara Fidelis Rodrigues: drafting the work or revising; final approval. 
Arthur Nicolato: conception or design of the work; acquisition, analysis, or interpretation of data for the work; drafting the work or revising; final approval.

Jose Augusto Malheiros: acquisition, analysis, or interpretation of data for the work.

\section{No acknowledgements.}

The authors have no personal, financial, or institutional interest in any materials, or devices described in this article.

\section{References}

1. Abecassis IJ, Sen RD, Ellenbogen RG, Sekhar LN (2020) Developing microsurgical milestones for psychomotor skills in neurological surgery residents as an adjunct to operative training: the home microsurgery laboratory. $J$ Neurosurg 1-11. doi: 10.3171/2020.5.JNS201590.

2. Car J, Sheikh A, Wicks P, Williams MS (2019) Beyond the hype of big data and artificial intelligence: building foundations for knowledge and wisdom. BMC Med 17(1):143. doi: 10.1186/s12916-019-1382-x.

3. de Montbrun S, Roberts PL, Satterthwaite L, MacRae H (2016) Implementing and evaluating a national certification technical skills examination: the Colorectal Objective Structured Assessment Of Technical Skill. Ann Surg 264:1-6. doi: 10.1097/SLA.0000000000001620.

4. de Oliveira MMR, Ferrarez CE, Ramos TM, Malheiros JA, Nicolato A, Machado CJ, Ferreira MT, de Oliveira FB, de Sousa CFPM, Costa PHV, Gusmao S, Lanzino G, Maestro RD (2018) Learning brain aneurysm microsurgical skills in a human placenta model: predictive validity. J Neurosurg 128:846-852. doi:

10.3171/2016.10.JNS162083.

5. Forestier G, Riffaud L, Petitjean F, Henaux PL, Jannin P (2018) Surgical skills: Can learning curves be computed from recordings of surgical activities? Int J Comput Assist Radiol Surg 13(5):629-636. doi: 10.1007/s11548-018-1713-y.

6. Glaser B, Dänzer S, Neumuth T (2015) Intra-operative surgical instrument usage detection on a multi-sensor table. Int J Comput Assist Radiol Surg 10(3):351-362. doi: 10.1007/s11548-014-1066-0.

7. Masters K (2019) Artificial intelligence in medical education. Med Teach 41(9):976-980.

8. Mehrzad R, Prsic A, Basta M, Bhatt R (2019) A Cross-Sectional Survey Study among Hand Surgeons in the United States on Standardizing Microsurgery Training. J Hand Microsurg 11(1):35-44. doi: 10.1055/s-00381669365.

9. Mueller MA, Pourtaheri N, Evans GRD (2019) Microsurgery Training Resource Variation among US Integrated Plastic Surgery Residency Programs. J Reconstr Microsurg 35(3):176-181. doi: 10.1055/s-0038-1668160.

10. Oliveira MM, Araujo AB, Nicolato A, Prosdocimi A, Godinho JV, Valle ALM, Santos M, Reis AB, Ferreira MT, Sabbagh A, Gusmao S, Del Maestro R (2016) Face, content, and construct validity of brain tumor microsurgery simulation using a human placenta model. Oper Neurosurg 12:61-67. doi: 10.1227/NEU.0000000000001030.

11. Oliveira Magaldi M, Nicolato A, Godinho JV, Santos M, Prosdocimi A, Malheiros JA, Lei T, Belykh E, Almefty RO, Almefty KK, Preul MC, Spetzler RF, Nakaji P (2014) Human placenta aneurysm model for training neurosurgeons in vascular microsurgery. Neurosurg 10(Suppl 4):592-601. doi:

10.1227/NEU.0000000000000553.

12. Ribeiro de Oliveira MM, Nicolato A, Santos M, Godinho JV, Brito R, Alvarenga A, Martins AL, Prosdocimi A, Trivelato FP, Sabbagh AJ, Reis AB, Maestro RD (2016) Face, content, and construct validity of human placenta 
as a haptic training tool in neurointerventional surgery. J Neurosurg 124:1238-1244. doi:

10.3171/2015.1.JNS141583.

13. Sains $P$, Chana KS, Sridhar V, Sajid MS (2018) Pilot study on an innovative biosensor with a range of medical and surgical applications. BMC Res Notes 11(1):81. doi: 10.1186/s13104-018-3163-6.

14. Tolba RH, Czigány Z, Osorio Lujan S, Oltean M, Axelsson M, Akelina Y, Di Cataldo A, Miko I, Furka I, Dahmen U, Kobayashi E, lonac M, Nemeth N (2017) Defining Standards in Experimental Microsurgical Training: Recommendations of the European Society for Surgical Research (ESSR) and the International Society for Experimental Microsurgery (ISEM). Eur Surg Res 58(5-6):246-262. doi: 10.1159/000479005.

\section{Tables}

Table 1 - Proficiency index in microsurgical education (PRIME) of 5 medical doctors simulating placenta arteriotomy and micro-suture in 3 different sessions done by each participant 


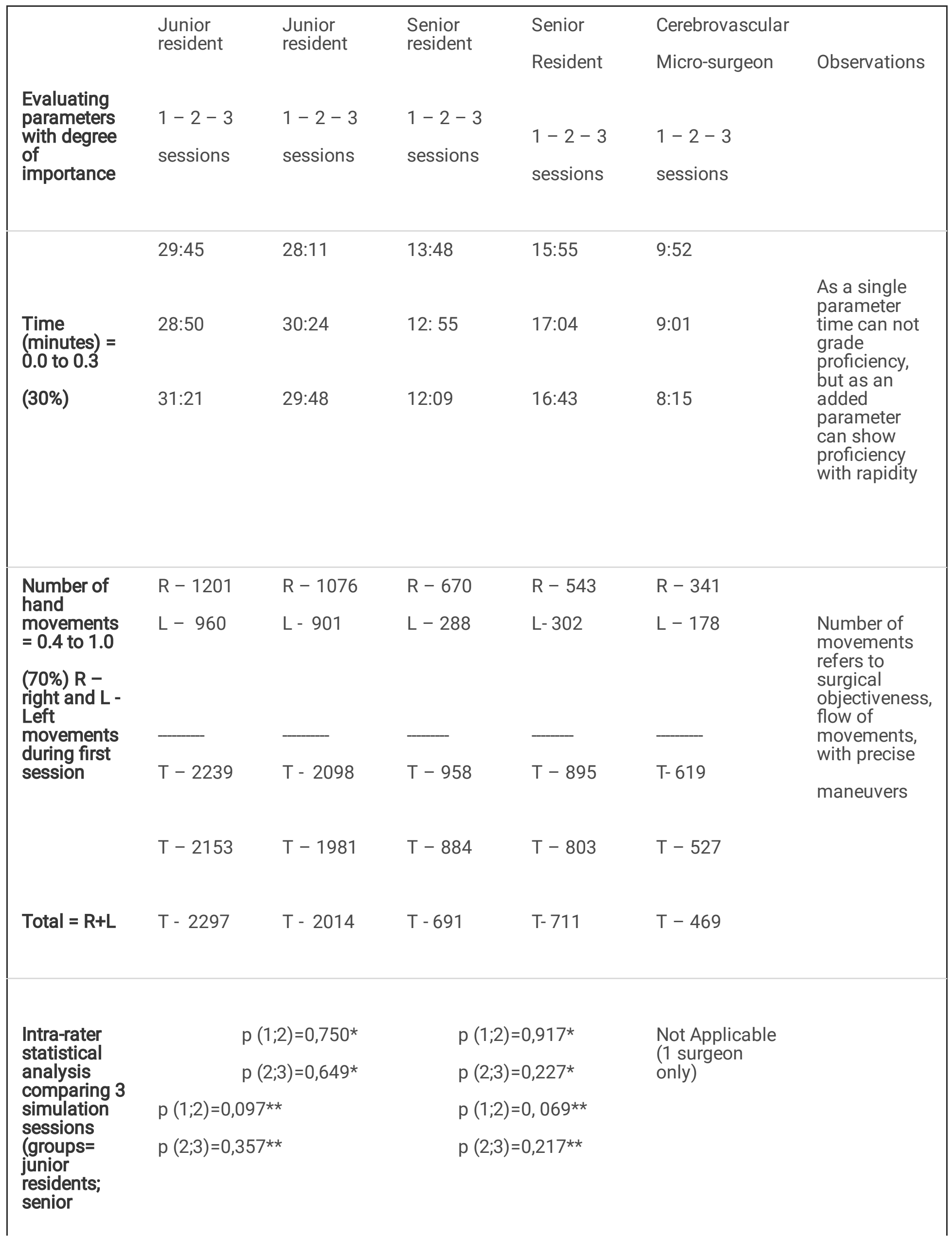




\begin{tabular}{|c|c|c|c|c|c|}
\hline Obse & $\begin{array}{l}\text { No } \\
\text { reduction } \\
\text { of } \\
\text { movements } \\
\text { on essays }\end{array}$ & $\begin{array}{l}\text { No } \\
\text { reduction } \\
\text { of } \\
\text { movements } \\
\text { on essays }\end{array}$ & $\begin{array}{l}\text { Improved } \\
\text { time and } \\
\text { number of } \\
\text { movements } \\
\text { in less than }\end{array}$ & $\begin{array}{l}\text { Improved } \\
\text { time and } \\
\text { number of } \\
\text { movements } \\
\text { around }\end{array}$ & $\begin{array}{l}\text { Improved time } \\
\text { and number of } \\
\text { movements } \\
\text { around } 30 \%\end{array}$ \\
\hline & & & $20 \%$ & $25 \%$ & \\
\hline
\end{tabular}

Notes: * $p$ value for differences in time (minutes) between sessions: $p(1,2)$ - difference between sessions 1 and 2; $p(2,3)$ - difference between sessions 2 and 3 . ** $p$ value for differences in total number of hands movement (minutes) between sessions: $p(1,2)$ - difference between sessions 1 and 2; $p(2,3)$ - difference between sessions 2 and 3

\section{Figures}

\section{Image not available with this version}

Figure 1

Endpoints for feedback regarding microsurgical performance analysis consisted of total time to execute proposed tasks and number of right and left hand movements (Table 1) (Figure 1).

\section{Supplementary Files}

This is a list of supplementary files associated with this preprint. Click to download.

- 803960video1440543q6966I.mp4 